\title{
试用中子活化法测定我国华南热带和 亚热带某些地表水地球化学背景值
}

\author{
王景 华 \\ (中国科学院地理研究所) \\ 李岫霞 毛雪菜 钱杏珍 柴之芳 \\ （中国科学院高能物理研究所）
}

中子活化法测定地表水地球化学背景值是一项新的分析技术. 目前, 这个方法已经在我 国应用. 我们收集了一些没有污染的海南岛热带和广东省西部亚热带地表水样品, 这些样品 经冷冻干燥以后用中子活化法进行分析. 共分析 28 个元素. 这些都是取自不同地点的河水 和水库水, 分析结果表明, 地表水地球化学背景值与热带、亚热带的生物一气候条件和岩石的地 球化学成分有关.

\section{一、样品介绍}

海南岛热带和广东省西部亚热带自然地理环境是非常复杂的. 强烈的风化作用和淋溶作 用对地表水化学成分有重要影响. 在热带和亚热带研究地表水背景值, 不仅要考虑污染, 而且 应考虑土壤、生物和岩石的强烈地球化学作用 ${ }^{[1]}$.

海南岛热带和广东省西部亚热带地表水样品情况如下:

1. 发育在热带季雨林玄武岩裂隙的温泉水: 样品采自海南岛兴隆温泉, 水温 $70^{\circ} \mathrm{C}$.

2. 发育在海南岛五指山热带季雨林, 五指山河源的河水. 河水流自流纹岩和粗面岩组成 的山裂隙中, 土壤是山地黄壤.

3. 发育在海南岛五指山热带季雨林, 五指山河水. 样品采自五指山河毛祥村, 它汇集了五. 指山淋溶作用带来的物质.

4. 发育在雷州半岛热带砖红壤的水库水. 样品采自余庆水库. 有一定汇水面积, 并且集 水在深厚的砖红壤红色盆地中,基底岩石是玄武岩.

5. 发育在湛江南亚热带的湖水. 样品采自湖光岩, 它是玄武岩火山口湖, 没有其它地表水 进入.

6. 发育在广东西部亚热带的高山水. 样品采自大田顶山岩石裂隙中, 海拔 1703.9 米.

\section{二、分析 方法}

取样品 100 毫升, 经过 0.45 微米的微孔誌膜, 除去悬浮物质后, 用液氮冻成冰. 然后放 在真空度为 $1 \times 10^{-3}$ 毫米手柱的冷冻干燥装置中进行冰的低温升华, 干燥后的残渣转移至石 英瓶, 与标准同时放入反应堆中照射 20 小时. 经简单化学处理后, 用 Scorpio 3,000r 谱仪 (美 国 Canberra 公司出品) 测 $r$-谱. $\mathrm{Ge}(\mathrm{Li})$ 探测器的灵敏体积为 $136 \mathrm{~cm}^{3}$, 分辨率 $1.85 \mathrm{KeV}$ (对 ${ }^{60} \mathrm{Co}$ 的 $1332 \mathrm{KeV} \gamma$ 射线).

本文 1980 年 5 月 24 日收到。 


\section{三、结果和讨论}

分析结果列入表 1 中, 测定的元素有 28 个, 它们的情况是这样的 ${ }^{[2,3]}$ :

1.28 个元素可以分成三组, 见表 2.

表 1 我国华南热带和亚热带地表水地球化学背景值(p.p. b.)

\begin{tabular}{|c|c|c|c|c|c|c|}
\hline 元 素 & 温 泉 水 & $\begin{array}{l}\text { 互指山河 } \\
\text { 水(河源) }\end{array}$ & $\begin{array}{c}\text { 五指山河水 } \\
\text { (昌祥村) }\end{array}$ & 余庆水库水 & 湖光岩湖水 & 大田顶山高 \\
\hline As & 34.0 & 3.3 & 11.0 & 5.9 & 2.5 & 2.0 \\
\hline $\mathrm{Au}$ & 0.00063 & - & 0.00028 & - & 0.00043 & - \\
\hline $\mathrm{Br}$ & 130 & 4.6 & 9.0 & 320 & 22.0 & 12.0 \\
\hline $\mathrm{Cd}$ & 7.8 & 0.29 & - & 1.0 & - & 2.2 \\
\hline $\mathrm{La}$ & 0.056 & 0.014 & 0.030 & 0.061 & 0.014 & 0.028 \\
\hline Mo & 0.52 & - & - & - & -- & - \\
\hline $\mathrm{Na}$ & 170000 & 6100 & 5900 & 5700 & 4700 & 3500 \\
\hline $\mathrm{U}$ & 0.40 & - & 0.24 & 0.038 & - & - \\
\hline $\mathrm{S}_{\mathrm{m}}$ & - & 0.0024 & 0.0047 & - & 0.0038 & 0.0017 \\
\hline $\mathrm{w}$ & 630 & 0.0085 & 0.14 & 0.61 & 0.22 & 0.86 \\
\hline $\mathrm{Cu}$ & 2.7 & 0.28 & 0.22 & 0.54 & 0.18 & 3.3 \\
\hline $\mathrm{K}$ & - & 3.9 & 1900 & 7300 & 8400 & - \\
\hline Co & 0.29 & 0.10 & 0.17 & 0.24 & 0.20 & 0.033 \\
\hline $\mathrm{Cr}$ & 0.33 & - & - & 0.40 & - & 0.44 \\
\hline Cs & 8.2 & 0.096 & 0.094 & 0.14 & 0.11 & 0.21 \\
\hline $\mathrm{Fe}$ & 19.0 & - & 56.0 & 23.0 & 66.0 & 46.0 \\
\hline $\mathrm{Hf}$ & - & - & - & 0.029 & 0.044 & 0.040 \\
\hline $\mathrm{Rb}$ & 25.0 & 1.4 & 4.1 & 2.0 & 4.2 & 3.1 \\
\hline $\mathrm{Sb}$ & 0.075 & 0.27 & 0.16 & 0.092 & 0.058 & 0.075 \\
\hline $\mathrm{Sc}$ & 0.0038 & 0.0019 & 0.0045 & 0.010 & 0.0044 & 0.0047 \\
\hline $\mathrm{Se}$ & - & - & 0.24 & 0.23 & - & - \\
\hline $\mathrm{Sr}$ & 100 & 9.7 & 15.0 & -- & 14.0 & - \\
\hline $\mathrm{Zn}$ & 5.8 & 18.0 & 53.0 & 92.0 & 5.0 & - \\
\hline $\mathrm{Th}$ & 0.028 & 0.017 & 0.016 & - & - & - \\
\hline $\mathrm{Ag}$ & 0.16 & 0.041 & - & 0.089 & 0.096 & 0.12 \\
\hline $\mathrm{Ba}$ & - & 9.2 & 17.0 & 16.0 & 18.0 & 8.1 \\
\hline $\mathrm{Ca}$ & 5400 & 3600 & 4800 & 4000 & 4400 & 2700 \\
\hline $\mathrm{Yb}$ & - & - & 0.083 & 0.064 & - & - \\
\hline
\end{tabular}

第一组, 易溶解在水中的地表大量出现的元素, 主要包括 $\mathrm{Na} 、 \mathrm{Ca} 、 \mathrm{~K}$ ，它们很容易在水中 迁移. 热带和亚热带土壤中含量极少. 除发育在玄武岩温泉中的 Na 含量达 170,000 p. p. b. 外,其它样品 $\mathrm{Na} 、 \mathrm{Ca} 、 \mathrm{~K}$ 都很少，与我国北方比较， $\mathrm{Na} 、 \mathrm{Ca}$ 都是最低.

第二组, 微量元素 $\mathrm{Cd} 、 \mathrm{Cr} 、 \mathrm{Sr} 、 \mathrm{Cu} 、 \mathrm{Ba} 、 \mathrm{Zn} 、 \mathrm{Fe} 、 \mathrm{Rb} 、 \mathrm{Se} 、 A s$ 在样品中出现的数值是: $\mathrm{n} \cdot 0.1-\mathrm{n} \cdot 10$ p. p. b.. 另外一些, $A u 、 M o 、 W 、 A g 、 C o 、 C s 、 H f 、 S c 、 S b$ 大约是: $\mathrm{n} \cdot 0.0001$ $\mathrm{n} \cdot 0.1$ p. p. b.

第三组, 锞系和钢系元素 $L a 、 S m 、 U 、 T h 、 Y b$ 含量大约是: $n \cdot 0.001-n \cdot 0.1$ p.p.b.

2. 我国热带和亚热带地表水中化学元素种类颇多, 含量亦不少. 与岩石的地球化学作用 有关, 运行于地下的天然水, 跟岩石接触过程中, 岩石中的化学成分受水溶蚀以后进入地表水

第 7 期

科学 通报

427 
表 228 个元索出现的范围值

\begin{tabular}{|c|c|}
\hline 元 & 出现范围值 (p.p.b.) \\
\hline $\mathrm{Na}, \mathrm{Ca}, \mathrm{K}$ & $\mathrm{n} \cdot 1.0-\mathrm{n} \cdot 100,000$ \\
\hline $\begin{array}{l}\mathrm{Cd}, \mathrm{Cr}, \mathrm{Sr}, \mathrm{Br}, \mathrm{Rb} \\
\mathrm{Cu}, \mathrm{Ba}, \mathrm{Zn}, \mathrm{Fe}, \mathrm{Se}, \text { As }\end{array}$ & $\mathbf{n} \cdot 0.1-\mathbf{n} \cdot 10$ \\
\hline $\begin{array}{l}\mathrm{Au}, \mathrm{Mo}, \mathrm{W}, \mathrm{Ag}, \mathrm{Co}, \mathrm{Cs} \\
\mathrm{Hf}, \mathrm{Sc}, \mathrm{Sb}\end{array}$ & $\mathrm{n} \cdot 0.0001-\mathrm{n} \cdot 0.1$ \\
\hline $\mathrm{La}, \mathrm{Sm}, \mathrm{U}, \mathrm{Th}, \mathrm{Yb}$ & $\mathbf{n} \cdot 0.001-\mathrm{n} \cdot 0.1$ \\
\hline
\end{tabular}

中,发育在玄武岩的温泉水,水中元素含量要高于其它样品. 如As含量达到 34p.p. b.

3. 生物一气候条件和土壤的淋溶作用使一些元素进入地表水中,改变和增高了地表水元素 的含量. 例如, 水库水和五指山河水(毛祥村), 都有一定的汇水面积,它们汇集了周围淋溶物 质,因此,元素的含量要高于河流上游和高山顶部的含量.

\section{考文献}

[1] Durum, W. H. \& Haffty, J., Geochime et Cosmochim Acta, 27 (1963), 1-11.

[2] Taylob, S. R., Geochime et Cosmochim Aota, 28(1964), 1273.

[3] Shaw, D. M., Geochime et Cosmochim Acta, 23(1961), 116-134. 